\section{Long Term Immunologic Consequences of Illicit Drug}

\section{Abuse}

\section{Obinna Nnorom-Dike*, Osmond Ekwebelem, Ekene Ofielu, Micheal Attah and David Ekwe}

Department of Microbiology and Immunology, University of Nigeria, Nsukka, Nigeria

\begin{abstract}
The increased susceptibility to infections among illicit drug users has gained immense interest. Over the past three decades, the effects of illicit drugs on the immune system have been subject to research predominantly in animals; while relatively little studies have been done in humans. This review focuses exclusively on reported effects of illicit drugs (Cocaine, Marijuana and Opioids) on the immune cell function in human. The emerging picture suggests that the contribution of illicit drugs to the global burden of disease and death are large and troubling. Reported consequences hint that cocaine can compromise the integrity of the immune system through direct effects on lymphocyte responses, particularly Natural Killer (NK) cells. Marijuana the most commonly used illicit drug, affects the number, proliferation and sensitivity of important immune cells such as $T$ cells, B cells and NK cells by directly inhibiting immune cell migration to tissues. Similarly, opioid suppresses the immune system through direct or indirect pathways that leads to the release of corticosteroid and immunosuppressive hormones, thereby resulting to immune system suppression. This decreased immune responsiveness in illicit drug abusers is believed to be responsible for the increased susceptibility to viral infections. Therefore, beyond the prevalence of illicit drug use and dependence, medical practitioners and illicit drug users should be aware of the flipsides associated with this disorder, particularly the immunologic downsides.
\end{abstract}

Keywords: Cocaine; Illicit drugs; Immune system; Marijuana; Opioid

\section{Introduction}

Over the past decade, the increased susceptibility to infections among illicit drug users has become more widely acknowledged. The

${ }^{\star}$ Corresponding author: Obinna Nnorom-Dike, Department of Microbiology and Immunology, University of Nigeria, Nsukka, Nigeria, Tel: +234 8160641402 , Email: obinna.nnorom-dike.199535@unn.edu.ng

Citation: Dike ON, Ekwebelem O, Ofielu E, Attah M, Ekwe D (2020) Long Term Immunologic Consequences of Illicit Drug Abuse. J Alcohol Drug Depend Subst Abus 6: 022.

Received: November 16, 2020; Accepted: December 04, 2020; Published: December 09, 2020

Copyright: (c) 2020 Dike ON, et al. This is an open-access article distributed under the terms of the Creative Commons Attribution License, which permits unrestricted use, distribution, and reproduction in any medium, provided the original author and source are credited. rampant use of illicit drugs is creating countless problems for society. Currently, illicit drug abusers are the largest growing segment of the population becoming infected with the human immunodeficiency virus (HIV) [1]. Over the years, there have been notable changes in the clinical manifestations of these psychoactive drugs due to several modifications in their contents and manufacturing processes. Contrary to expectations, the magnitude of this problem continues to increase in many parts of the world. Illicit chemists are compounding and synthesizing new designer illicit drugs faster than society can make them illegal [2]. The inability of standard clinical laboratory urine and blood drug screenings to routinely detect most of these drugs has left law enforcement agencies and clinicians handicapped in evaluating the patient who presents psychiatric, neurologic, cardiovascular and immunologic complications linked with illicit drug use [3]. However, it is difficult to estimate the magnitude of illicit drug abuse and the risk to public health [4]. Although the data have limitations and are incomplete, global estimates indicates that most of the illicit drugs came from shops $(57.68 \%)$, friends $(31.46 \%)$, and dealers $(10.1 \%)$ [3]. The users of illicit drugs experienced happy/ euphoric mood (57.7\%), talkativeness (42.5\%), and hallucinations (22.8\%); however, $74 \%$ experienced adverse reactions (immunologic reactions) with $4.9 \%$ requiring hospitalizations [3]. Increasing the risk of HIV transmission, disease progression, and less adherence to the antiretroviral therapy, which significantly contribute to morbidity and mortality of the HIV infected patients have been reported as the role illicit drugs of abuse play $[5,6]$.

Cocaine, opioid and marijuana abuse increases the viral disease progression by affecting host immune function, promoting the virus entry into the immune cells and replication, and also causes severe neurocognitive disorders by inducing neuro-inflammation [7,8]. Although gut microbiota contributes immensely in regulating immune homeostasis, both HIV and illicit drugs are notoriously acknowledged for its potential to disrupt gut homeostasis, gut immunity, and microbial translocation that may result to the accelerated viral disease progression [1]. While injection drug use is the second most common route for the HIV transmission, alcohol consumption, smoking, inhaling, and ingesting drugs such as cocaine, opioid (codeine and morphine) and marijuana will increase the risk of contracting HIV infection [9].

The devastating role the internet plays in the ease and speed with which new illicit drugs are distributed and in many cases before they have been identified or made illegal by authorities cannot be overlooked [10]. Multi-factorial actions which include education, social approaches, and medical and legal interventions are paramount in the prevention of illicit drug use.Passive and active vaccines against the drugs have been investigated in both preclinical and clinical trials as possible immunotherapies to thwart drug abuse. However, vaccines targeting cocaine, nicotine, phencyclidine, morphine, and methamphetamine have shown little potential [11]. Although these vaccines have potential, when widely available, long-term medical and psychological programs will most likely still be included as combination, to insure the abuser relearns constructive behaviors and control 
impulse and cravings effectively [4]. At the moment, clinicians will have to stay alert for new illicit drugs of abuse and recognize their clinical manifestations and immunological consequences.

\section{Immunologic Consequences of Cocaine}

Studies over the last decade have reported increased susceptibility to infections among illicit drug users, especially cocaine users [12,13]. Cocaine, alternatively called cocain or coke is one of the most widely consumed illicit drugs amongst young adults worldwide and also associated with significant consequences [14]. In order to maintain homeostasis, the brain and the immune system must continuously cross-talk through soluble factors such as; cytokines, hormones and neurotransmitters [15]. This nonstop communication is organized along two main important pathways, making up the autonomic nervous system and the neuroendocrine axis $[15,16]$. Disruption of homeostasis, by either internal or external stressors, leads to the activation of these two pathways, which results in elevated peripheral levels of catecholamine (particularly noradrenalin) and cortisol respectively $[15,16]$. These increased levels of catecholamine and cortisol will in turn activate or alter immune function by binding to their matching receptors on immune cells [16]. Interestingly, reports have shown that the effects of cocaine on both the sympathetic nervous and endocrine systems appear to imitate the same stress response [17]. The increase in Natural Killer cells (NK-cells) has also been exemplified as effects of stress and cocaine on immune cells, which has been reported in response to either acute stress or cocaine exposure [18-20]. Chronic stress, however, has been associated with a down-regulation in NK-cell activity [21], especially in stimulant-addicted individuals. Conceivably, the observed disparities in NK-cells in cocaine-addicted individuals may not only be associated to cocaine's direct effects on immune cells, but may also be caused by cocaine's modulatory effects on neuroendocrine hormones [17].

Cocaine increases monoamine levels in the brain and in the periphery, where it interacts with immune cells. It is believed that the neurotransmitter 'dopamine' also plays a pivotal role in regulating immunity [22]. Dopamine receptors are expressed on various lymphocyte subpopulations (such as T-cells, B-cells and NK-cells), where they function in the regulation of proliferation, differentiation and apoptosis of these cells [23]. When cocaine binds to the dopamine transporter in peripheral lymphocytes, cocaine may be able to directly modulate immune functions [24]. Dopamine has, however, been reported to act as a mediator between the brain and the immune system, given its involvement in both [25]. This poses the question of whether the notoriously researched central nervous dopamine dysfunction in cocaine addiction is also accompanied by changes in the number, proportion and function of CD4+ (Cluster of Differentiation 4) and CD8+ (Cluster of Differentiation 8) lymphocytes, Natural Killer (NK) cells, and macrophages in the periphery. Despite limited studies in humans, emerging literatures have reported that cocaine acutely affects the number and activity of specific lymphocyte populations, including CD4+, CD8+ and NK-cells $[18,19,26]$. Whether these changes are long lasting still remains unclear, as reports in cocaine-addicted individuals are inconsistent $[18,27]$. Prolonged dopamine induced activation is responsible for the suppression of NK-cell proliferation [28], which would be a possible scenario in cocaine addiction. Considering the major role that NK-cells play in anti-viral immune defense, these undesired changes in the levels of NK-cells may have severe consequences on immunity.
The increasing knowledge about the effects of cocaine on immune system has raised concerns around whether using cocaine is associated with an increased risk for infections, and also with more rapid and severe progression of a contracted infectious disease. An interaction between cocaine and a virus has been shown for the human immunodeficiency virus (HIV), but this may well apply to other infections [29]. One example of such an interaction involves the dopamine transporter (DAT), to which both the HIV-TAT protein (Trans-Activator of Transcription) and cocaine bind. The inhibition of DAT by cocaine leads to increased extracellular levels of dopamine which consequently blocks dopamine reuptake, TAT-protein functions as an allosteric modulator of the DAT [29]. This increase in dopamine concentration will result in an increment of inflammatory macrophages and greater permeability of the blood-brain-barrier, which in turn promotes the progression of HIV-associated pathology. Significantly, the complexity associated in the interactions between cocaine and HIV are not limited to the DAT. Additional mechanisms such as cocaine-induced enhancement of HIV transcription and expression have also been reported $[29,30]$. Therefore, increased inflammation, accelerated progression of the infection and enhanced development of the HIV-associated neurocognitive disorder are the worst clinical outcome associated with using cocaine during HIV infection.

Consequently, it is also possible that cocaine's immunologic consequences may relate to other notable effects associated with cocaine addiction, such as low body weight and poor sleep quality [31]. Even though the long term negative consequences of regular cocaine addiction are most prominent in the domain of psychosocial functioning, the wide range medical complications frequently witnessed in chronic cocaine users has been increasingly getting attention in the last decade $[32,33]$.

\section{Immunologic Consequences of Opioid}

Over the years, codeine has been the most commonly abused opioid, and this is a growing problem worldwide. Although the majority of the abusers use it for recreational purposes, many got addicted to it after using it as a medication to relief pain and cough. Codeine, derived from opium poppy plant, is essentially used in the treatment of mild to moderate pain $[5,34,35]$ and as a cough suppressant $[5,36]$ which is similar to morphine and hydrocodone [37]. However, evidence does not support its use for acute cough treatment in children or adults [38]. Like other opiates, codeine binds to opium receptors found on the pain signaling neurons causing molecular and cellular changes that prevent these neurons from sending signals to each other thereby stopping a person's sensation of pain. Thus, codeine possesses significant central analgesic property, so it is widely used to relieve pains in patients suffering from cancer and in head trauma [37]. It has also been used in the treatment of diarrhea [5,34]. Codeine and its opioid relatives are increasingly replacing the scarce hard drugs like cocaine, indian hemp, and heroin [38,39], and they are mostly consumed by young adults and teenagers [34]. These drugs could cause hyperactivities, depression, inflammation, hyperpsycoactivities, and other psychiatric disorders [38,39]. Codeine can produce adverse effects such as cutaneous symptoms such as; itching, rash, urticaria, angioedema, erythema nodosum, erythema multiforme,occupational eczema. It also causes bronchospasm (respiratory disorder), and hypotension, when administered intravenously [40].

In addition to the above mentioned consequences, codeine and its opiate group have severally been demonstrated to have immunosuppressive potential. Opioids modulate both the innate and adaptive 
immune system by binding to the Mu Opioid Receptor (MOR) and ultimately resulting to an impaired ability of the host to clear pathogens [41]. Opioid receptors are expressed throughout the body, in various tissues and cell types [42]. Previous studies have found that there are many opioid receptors on different kind of immune cells [43-45], such as the T cells, B cells and macrophages [42].These findings suggest that opioids may be directly mediating their various arrays of effects by binding to opioid receptors expressed on the immune cells. For instance, a number of studies have reported that a significant degree of cross-talk can occur between the opioid receptors and the chemokines and chemokine receptor families [46]. Both the receptors of opioids and chemokines belong to the class of G Protein Coupled Receptors (GPCRs). Thus, a chemokine receptor can be blocked from signaling after binding its ligand when an opioid receptor binds its ligand. The effects of opioids on the immune system have been investigated in patients with prolonged use or people with a history of opioid abuse. The results demonstrated that these people are more susceptible to infectious agents than non-opiate users [34].

The prevalence of HIV, hepatitis B and C, tetanus and malaria are also frequently observed among these patients [41]. Codeine-induced immunological suppression is likened to its opiate family pattern. Opiates suppress the immune system through either direct or indirect pathways. Direct immunosuppressive pathway requires direct interaction of the opioid on the mu receptor on the immune cells. In indirect process, the opioid acts on the Central Nervous System (CNS) and the Hypothalamic Pituitary Adrenal (HPA) axis which leads to the release of corticosteroid and immunosuppressive hormones thereby leading to the suppression of the immune system [42]. Olaniyan, et al. [34] demonstrated the immunological response of rabbits administered with codeine at both low and high doses using cortisol, an anti-inflammatory agent. Cortisol is released in the body in response to inflammation, low blood-glucose concentration and stress. It stimulates gluconeogenesis [47], to suppress the immune system [34]. Their experiment demonstrated significantly lower level of cortisol in the plasma among rabbits fed with codeine containing meals when compared to those fed with normal meals. The low concentration of cortisol in the plasma was attributed to its excessive utilization to reduce inflammation, a consequence of codeine treatment [48].

Immuno-modulative activity among opiates depends on the type administered independent of the duration of action or its potency. Typical example is the hydromorphone which has high potency, short action time and not immunosuppressive [41]. In a comparative study, Sarcerdote, et al. [49] reported that codeine induces a partial immunosuppressive activity which leads to significant decrease in natural killer cell (NK) activity and interleukin-2 production. This study also demonstrated that morphine, a derivative of codeine, had stronger immunosuppressive activity than its parent drug [49]. The reason for the difference in their immunosuppressive properties was linked to their structural difference. This was as a result of the modification at the $\mathrm{C} 3$ position; codeine differs from morphine for the methyl substitution at C3. Morphine suppresses; NK cell activity, T cell and B cell responses to mitogens, antibody production and $\mathrm{T}$ cell mediated adaptive immune response, alongside down-regulation of cytokine and chemokine production by macrophages, microglia and astrocytes [50].

Results have indicated that codeine activates mast cells. Larger concentrations of codeine and other opioids induce the activation of mast cells resulting to the liberation of mast cell mediators; histamine and tryptase in humans [48,51], with codeine, morphine and pethidine having the greatest histamine-releasing potential [40]. Blunk et al. [51] demonstrated that this activation is not dependent on the mu receptors, but more likely, on the direct activation of G-proteins of mast cells. However, this is contrary to earlier publications postulating the involvement of the mu receptors on the histamine release from mast cells [52]. Sheen, et al. [48] also suggested that mast cell degranulation may occur via the d-opioid receptor or the activation of the G-proteins of mast cells but not via the mu receptor. Codeine-induced activation of mast cell does not only result in the release of histamine, but can also induce the release of cytokines and chemokines which can recruit and activate $\mathrm{T}$ cells, eosinophils and other inflammatory cells. Thus, codeine use can also result to late cutaneous allergic inflammation through the production of these chemokines [48].

\section{Immunologic Consequences of Marijuana}

Marijuana or Cannabis as it is also called is among the very oldest economic plants providing humans with fiber for spinning, weaving cloth, and making paper. Marijuana also provides seed for human foods and livestock feeds, as well as aromatic resin containing compounds of pleasure and medicinal value. Human selection for varying uses and natural selection pressures imposed by diverse introduced climates has resulted in a wide variety of growth forms and chemical compositions. Over the years, marijuana has been the most commonly abused drug in the world. The illicit use of marijuana is not without significant health consequences. Marijuana is associated with effects on almost every organ system in the body, ranging from the central nervous system to the cardiovascular, endocrine, respiratory/ pulmonary, and immune systems. The plant marijuana contains more than 60 distinct chemicals called cannabinoids. Among them, D9-tetrahydrocannabinol (D9-THC) is the main psychoactive constituent, which was first structurally described in 1964 [53] and provided the name for this class of compounds. Cannabinoid effects on cellular immunity have been observed since 1970, when the first studies on marijuana smoking and its effect on the immune cells were reported. Since then, the effects of cannabinoids on immune function have been extensively studied.

Cannabinoids can influence $\mathrm{T}$ cell immunity in various manners. They can affect $\mathrm{T}$ cell number and proliferation, but may also have important effects on $\mathrm{T}$ helper1 and 2 specific cytokines and TGF-b (transforming growth factor beta) secretion [54], as well as T cells response to viral infections. When an individual has low $\mathrm{T}$ cells the individual becomes more susceptible to viral infection. Low $\mathrm{T}$ cell count is also a sign that the immune system is not functioning properly, by extension abusers of marijuana who are HIV positive will progress into AIDS faster because of low CD4 count. Initial studies done on $\mathrm{T}$ cells from blood of marijuana abusers showed an inhibitory effect such as decreases in number or sensitivity [55], but other studies failed to confirm these findings. This variability of results can be partly explained by the heterogeneity of the studies, with different routes of administration, type and quantity of marijuana used, THC (tetrahydrocannabinol) concentration, frequency of smoking and duration of inhalation. Secondly, moderate marijuana smoking has different effects on immune cells exposed directly to smoke than on cells of systemic immunity [56]. Alveolar macrophages in smokers have less cytokine production and responsiveness and lesser antimicrobial activity [56-58]. Acute exposure-related immune effects have also to be distinguished from those produced by chronic exposure to cannabinoids that may result in modulation of CBR (Cannabinoid 
Citation: Dike ON, Ekwebelem O, Ofielu E, Attah M, Ekwe D (2020) Long Term Immunologic Consequences of Illicit Drug Abuse. J Alcohol Drug Depend Subst Abus 6: 022 .

Receptor) expression, decreasing in $\mathrm{T}$ cell number and increased incidence of infection and head and neck squamous carcinoma $[55,43]$.

Cannabinoid compounds present in marijuana affects number of B cells, proliferation of B cells, their migration, and Immunoglobulin (Ig) production or isotype switching [54]. B cells are responsible for fighting bacterial infection; hence low B cell count makes an individual to be immune compromised. B cells, IgG and IgM, and some complement proteins are decreased in marijuana users [55] and antibody production in smokers' blood is differentially influenced by marijuana ingestion $[59,60]$. Also, antibody production is suppressed in splenocyte cultures by either synthetic corn plant CBR (Cannabinoid Receptor) ligands, possibly by a G-protein-coupled receptor mechanism [61]. Recently, it was shown that tetrahydrocannabinol (THC) can induce dose-related immune suppression in both the primary and secondary in vitro plaque-forming cell assays of antibody formation, via CB2R (Cannabinoid Receptor Type 2) receptors [62]. $\mathrm{B}$ cell proliferation and migration can be differentially influenced by cannabinoid ligands, in cell subsets (Th1 and Th2). The effects on the more recently described $\mathrm{Th} 17$ subsets have not been extensively studied. Cannabinoids produce a biasing in the balance between the two types of Th cells, suppressing Th1 and enhancing Th2, both CB1R (Cannabinoid Receptor Type 1) and CB2R being involved in this immune deviation [63]. In addition, the natural killer cells (NK) are effector lymphocytes of the innate immune system that is in charge of the control of several types of microbial infections by reducing their spread and subsequent tissue damage. NK cell numbers are reduced by the intake of "bhang", a form of marijuana extracted from cannabis leaves and used as a drink or smoked [55]. Various studies on human has shown that both proliferation and cellular cytolytic activity can be influenced by cannabinoid treatment, reducing the functions of NK cells and these effects can be mediated by CB1R and CB2R $[61,64]$.

\section{Conclusion}

The use of illicit drugs continues to expand without limitations to all corners of the world, social status, race, or education. From the existing data, it is clear that cocaine, marijuana and opioids such as codeine and morphine, increase susceptibility to infections especially viral infection like HIV. Patterns are emerging that indicate illicit drugs suppress a number of measures of cell-mediated and humoral-mediated immunity. Infectious disease models also suggest an overall decrease in immunocompetence. The increasing epidemic of illicit drug use necessitates further investigation of its effects on immunocompetence, so as to curb the rapidly rising incidence of HIV and other infectious diseases.Furthermore, these known consequences of cocaine, marijuana and opioids on immune function can help us to better understand how these disorders can be regulated pharmacologically.

\section{Conflicts of Interest}

The authors have no conflicts of interest to disclose.

\section{Funding}

This research received no external funding.

\section{Authors' Contributions}

This work was carried out in collaboration among all authors. Authors OVN and OCE conceived and designed the study. Authors
OVN, OCE and ESO searched and reviewed the literature and drafted the manuscript. Authors AM and DCE edited the manuscript. All authors read and approved the final manuscript for publication.

\section{References}

1. Atluri VSR, Kanthikeel SP, Samikkannu T, Sagar V, Kurapati KR, et al. (2016) Vorinostat positively regulates synaptic plasticity genes expression and spine density in HIV infected neurons: role of nicotine in progression of HIV-associated neurocognitive disorder. Mol Brain 7: 37.

2. Davis CG (2012) Drug abuse: newly-emerging drugs and trends. Clinics Lab Med 32: 407-414.

3. Bilinski P, Skrzpczal LK, Jablonski P (2012) Determining the scale of designer drugs (DD) abuse and risk to public health in Poland through epidemiological study in adolescents. Annals Agric Environ Med 19: 357-364.

4. Albertson TE (2014) Recreational Drugs of Abuse. Clin Rev Allergy Immunol 46: 1-2.

5. Anil SS, Ratnakaran B, Suresh N (2017) A case report of over-the-counter codeine dependence as consequence of self-medication for premature ejaculation. J Family Med Prim Care 6: 867-869.

6. Anthony JC, Vlahov D, Nelson KE, Conn S, Astemborski J, et al. (1991) New evidence on intravenous cocaine use and the risk of infection with human immunodeficiency virus type 1. Am J Epidemiol 134: 1175-1189.

7. Roy S, Ninkovic J, Banerjee S, Charboneau RG, Das S, et al. (2011) Opioid drug abuse and modulation of immune function: consequences in the susceptibility to opportunistic infections. J NeuroimmunePharmacol 6 : 442-465.

8. Smith DB, Simmonds P, Bell JE (2014) Brain viral burden, neuroinflammation and neuro degeneration in HAART-treated HIV positive injecting drug users. J Neurovirol 20: 28-38.

9. Friedland G, Vlahov D (2011) Integration of buprenorphine for substanceabuse treatment by HIV care providers. JAIDS J Acquir Immune DeficiencSyndr 56: 1-2.

10. Corazza O, Schifano F, Simonato P, Fergus S, Stair J, et al. (2012) Phenomenon of new drugs on the Internet: the case of ketamine derivative methoxetamine. Human Psychopharmacol 27: 145-147.

11. Peterson EC, Owens SM (2009) Designing immunotherapies to thwart drug abuse. MolInterv 9: 119-124.

12. Clark KH, Wiley CA, Bradberry CW (2013) Psychostimulant abuse and neuroinflammation: emerging evidence of their interconnection. NeurotoxicolRes 23: 174-188.

13. Mena G, Giraudon I, Alvarez E, Corkery JM, Matias J, et al. (2013) Cocaine-related health emergencies in Europe: a review of sources of information, trends and implications for service development. EurAddic Res 19: $74-81$

14. Jones L, Bartes G, Bellis M, Beynon C, Duffy P, et al. (2011) A Summary of the Health Harms of Drugs. London: U.K. Department of Health.

15. Pellegrino T, Bayer BM (1997) In vivo effects of cocaine on immune cell function. J Neuroimmunol 83: 139-147.

16. Sternberg EM (2006) Neural regulation of innate immunity: a coordinated nonspecific host response to pathogens. Nat Rev Immunol 6: 318-328.

17. Halpern JH, Sholar MB, Glowacki J, Mello NK, Mendelson JH, et al. (2003) Diminished interleukin-6 response to proinflammatory challenge in men and women after intravenous cocaine administration. J ClinEndocrinolMetab 88: 1188-1193.

18. Ruiz P, Cleary T, Nassiri TM, Steele B (1994) Human T-lymphocyte subpopulation and NK cell alterations in persons exposed to cocaine. ClinImmunol 70: 245-250. 
Citation: Dike ON, Ekwebelem O, Ofielu E, Attah M, Ekwe D (2020) Long Term Immunologic Consequences of Illicit Drug Abuse. J Alcohol Drug Depend Subst Abus 6: 022.

19. Van Dyke C, Stesin A, Jones R, Chuntharapai A, Seaman W (1986) Cocaine increases natural killer cell activity. J ClinInvestig 77: 1387-1390.

20. Pike JL, Smith TL, Hauger RL, Nicassio PM, Patterson TL, et al. (1997) Chronic life stress alters sympathetic, neuroendocrine, and immune responsivity to an acute psychological stressor in humans. Psychosomatic Med 59: 447-457.

21. Dallman MF (1993) Stress update. Trends EndocrinolMetab 4: 62-69.

22. Basu S, Dasgupta PS (2000) Dopamine, a neurotransmitter, influences the immune system. J Neuroimmunol 102: 113-124.

23. Levite M (2016) Dopamine and T cells: dopamine receptors and potent effects on T cells, dopamine production in T cells, and abnormalities in the dopaminergic system in $T$ cells in autoimmune, neurological and psychiatric diseases. ActaPhysiol 216: 42-89.

24. Sarkar C, Basu B, Chakroborty D, Dasgupta PS, Basu S (2010) Theimmunoregulatory role of dopamine: an update. Brain BehavImmunun 24 525-528.

25. Pacheco R, Contreras F, Zouali M (2014) The dopaminergic system in autoimmune diseases. Frontiers Immunol 5: 1-17.

26. Gan X, Zhang L, Newton T, Chang SL, Ling W, et al. (1998) Cocaine infusion increases interferon-[gamma] and decreases interleukin-10 in cocaine-dependent subjects. ClinImmunol 89: 181-190.

27. Ruiz P, Berho M, Steele BW, Hao L (1998). Peripheral human T lymphocyte maintenance of immune functional capacity and phenotypic characteristics following in vivo cocaine exposure. ClinImmunol 88: 271-276.

28. Mikulak J, Bozzo L, Roberto A, Pontarini E, Tentorio P, et al. (2014) Dopamine inhibits the effector functions of activated NK cells via the upregulation of the D5 receptor. J Immunol 193: 2792-2800.

29. Dahal S, Chitti SVP, Nair MPN, Saxena SK (2015)Interactive effects of cocaine on HIV infection: implication in HIV-associated neurocognitive disorder and neuroAIDS. Frontiers Microbiol 6: 931.

30. Swepson C, Ranjan A, Balasubramaniam M, Pandhare J, Dash C (2016) Cocaine enhances HIV-1 transcription in macrophages by inducing p38 MAPK phosphorylation. Frontiers Microbiol 7: 823.

31. Ersche KD, Doffinger R (2017). Inflammation and infection in human cocaine addiction. CurrOpinBehavSci 3: 203-209.

32. Oliveira RJD, Carvalho F, Duarte JA, Proenca JB, Santos A, et al. (2012) Clinical and forensic signs related to cocaine abuse. Curr Drug Abuse Rev 5: 64-83.

33. European Monitoring Centre for Drugs and Drug Addiction EMCDDA (2007). Cocaine and Crack Cocaine: A Growing Public Health Problem. EMCDDA, Lisbon, Portugal.

34. Olaniyan MF, Ozuruoke DFN, Fapohunda JS, Afolabi T (2017) Immunological Effect of Tramadol, Codeine, Flunitrazepam on Plasma Cortisol (Antiinflammatory Agent), Cortisol Binding Globulin (Acute Phase Protein) and Total Bile Acid in Rabbits. J Adv Med Medic Res 23: 1-8.

35. Peechakara BV, Gupta M (2020) Codeine. In: StatPeerls. Treasure Island (FL): StatPeerls Publishing, Florida, US.

36. Yoo HS, Yang EM, Kim MA, Hwang SH, Shin YS, et al. (2014) A Case of Codeine Induced Anaphylaxis via Oral Route. Allergy Asthma Immunol Res 6: 95-97.

37. Bhandari M, Bhandari A,Bhandari A (2011) Recent updates on codeine. Pharm Methods 2: 3-8.

38. Paul IM (2012)Therapeutic options for acute cough due to upper respiratory infections in children. Lung 190: 41-44.

39. Shen H, He MM, Liu H, Wrighton SA, Wang L, et al. (2007) Comparative metabolic capabilities and inhibitory profiles of CYP2D6.1, CYP2D6.10, and CYP2D6.17'. Drug MetabDispos 35: 1292-300.
40. Lastra LP, Cadarso AI, Martos MMR, Pimiento AP, Cabreros MIR, et al. (2006). Pharmacological stimuli in asthma/urticarial. AllergolImmunopathol 34: 224-227.

41. Plein LM, Ritther HL (2017) Opioids and the immune system - friend or foe. Brit J Pharm 175: 2717-2725.

42. Ninkovic J, Roy S (2013) Role of the mu-opioid receptor in opioid modulationof immune function. Amino Acids 45: 9-24.

43. Roy S, Wang J, Kelschenbach J, Koodie L, Martin J (2006) Modulation of immune function by morphine: implications for susceptibility to infection. J Neuroimmune Pharm 1: 77-89.

44. Li ZH, Chu N, Shan LD, Gong S, Yin QZ, et al. (2009) Inducible expression of functional mu opioid receptors in murine dendritic cells. J Neuroimmune Pharm 4: 359-367.

45. Liang X, Liu R, Chen C, Ji F, Li T(2016) Opioid System modulates the immune function: a review. TranslPerioper Pain Med 1: 5-13.

46. Rogers TJ (2020). Bidirectional Regulation of Opioid and Chemokine Function. Frontiers Immunol 11: 94.

47. Khani S, Tayek JA (2001) Cortisol increases gluconeogenesisin humans: its role in the metabolic syndrome. CliniSci 101: 739-747.

48. Sheen CH, Schleimer RP, Kulka M (2007)Codeine induces human mast cell chemokine and cytokineproduction: involvement of G-protein activation.Allergy 62: 532-538.

49. Sacerdote P, Manfredi B, Mantegazza P, Panerai AE (1997). Antinociceptive and immunosuppressive effects of opiate drugs: a structure-related activity study. Brit J Pharm 121: 834-840.

50. Eisenstein TK (2019)The Role of Opioid Receptors in Immune System Function. Frontiers Immunol 10: 2904.

51. Blunk AJ, Schmelz M, Zeck S, Skov P, Likar R, et al. (2004)Opioid-Induced Mast Cell Activation and Vascular Responses Is Not Mediated by Opioid Receptors: An In Vivo Microdialysis Study in Human Skin. AnesthesAnalges 98: 364-70.

52. Harle DG, Baldo BA, Coroneos NJ, Fisher MM (1989) Anaphylaxis following administration of papaveretum. Case report: implication of $\operatorname{IgE}$ antibodies that react with morphine and codeine, and identification of an allergenic determinant. Anesthesiol 71: 489-494.

53. Gaoni Y, Mechoulam R (1964) Isolation, structure, and partial synthesis of an active constituent of hashish. J AmeChemSoc 86: 1646-1647.

54. Croxford JL, Yamamura T (2005) Cannabinoids and the immune system: potential for the treatment of inflammatory diseases? J Neuroimmunol 166: 3-18.

55. El-Gohary M, Eid MA (2004) Effect of cannabinoid ingestion (in the form of bhang) on the immune system of high school and university students. Human ExperimToxicol 23: 149-156.

56. Tanasescu R, Constantinescu CS (2010) Cannabinoids and the immune system: An overview. Immunobiol 215: 588-597.

57. Shay AH, Choi R, Whittaker K, Salehi K, Kitchen CM, et al. (2003) Impairment of antimicrobial activity and nitric oxide production in alveolar macrophages from smokers of marijuana and cocaine. J Infec Dis 187: 700-704

58. Klein TW, Newton C, Larsen K, Lu L, Perkins I, et al. (2003) The cannabinoid system and immune modulation. J Leukocyte Biol 74: 486-496.

59. Cabral GA, Raborn ES, Griffin L, Dennis J, Cabral FM (2008) CB2 receptors in the brain: role in central immune function. Brit J Pharm 153: 240-251.

60. Nahas GG, Osserman EF (1991) Altered serum immunoglobulin concentration in chronic marijuana smokers. Drugs of Abuse, ImmunImmunodef 112: $25-32$. 
Citation: Dike ON, Ekwebelem O, Ofielu E, Attah M, Ekwe D (2020) Long Term Immunologic Consequences of Illicit Drug Abuse. J Alcohol Drug Depend Subst Abus 6: 022 .

61. Massi P, Vaccani A, Parolaro D (2006) Cannabinoids, immune system and cytokine network. Curr Pharm Des 12: 3135-3146.

62. Eisenstein TK, Meissler JJ, Wilson Q, Gaughan JP, Adler MW (2007) Anandamide and Delta9-tetrahydrocannabinol directly inhibit cells of the immune system via CB2 receptors. J Neuroimmunol 189: 17-22.
63. Yuan M, Kiertscher SM, Cheng Q, Zoumalan R, Tashkin DP et al. (2002) Delta 9-Tetrahydrocannabinol regulates Th1/Th2 cytokine balance in activated human T cells. J Neuroimmunol 133: 124-131.

64. Nong L, Newton C, Cheng Q, Friedman H, Roth MD, et al. (2002) Altered cannabinoid receptor mRNA expression in peripheral blood mononuclear cells from marijuana smokers. J Neuroimmunol 127: 169-176. 


\section{Hif}

Advances In Industrial Biotechnology | ISSN: 2639-5665

Advances In Microbiology Research | ISSN: 2689-694X

Archives Of Surgery And Surgical Education | ISSN: 2689-3126

Archives Of Urology

Archives Of Zoological Studies | ISSN: 2640-7779

Current Trends Medical And Biological Engineering

International Journal Of Case Reports And Therapeutic Studies | ISSN: 2689-310X

Journal Of Addiction \& Addictive Disorders | ISSN: 2578-7276

Journal Of Agronomy \& Agricultural Science | ISSN: 2689-8292

Journal Of AIDS Clinical Research \& STDs | ISSN: 2572-7370

Journal Of Alcoholism Drug Abuse \& Substance Dependence | ISSN: 2572-9594

Journal Of Allergy Disorders \& Therapy | ISSN: 2470-749X

Journal Of Alternative Complementary \& Integrative Medicine | ISSN: 2470-7562

Journal Of Alzheimers \& Neurodegenerative Diseases | ISSN: 2572-9608

Journal Of Anesthesia \& Clinical Care | ISSN: 2378-8879

Journal Of Angiology \& Vascular Surgery | ISSN: 2572-7397

Journal Of Animal Research \& Veterinary Science | ISSN: 2639-375

Journal Of Aquaculture \& Fisheries | ISSN: 2576-5523

Journal Of Atmospheric \& Earth Sciences | ISSN: 2689-8780

Journal Of Biotech Research \& Biochemistry

Journal Of Brain \& Neuroscience Research

Journal Of Cancer Biology \& Treatment | ISSN: 2470-7546

Journal Of Cardiology Study \& Research | ISSN: 2640-768X

Journal Of Cell Biology \& Cell Metabolism | ISSN: 2381-1943

Journal Of Clinical Dermatology \& Therapy | ISSN: 2378-8771

Journal Of Clinical Immunology \& Immunotherapy | ISSN: 2378-8844

Journal Of Clinical Studies \& Medical Case Reports | ISSN: 2378-880

Journal Of Community Medicine \& Public Health Care | ISSN: 2381-1978

Journal Of Cytology \& Tissue Biology | ISSN: 2378-9107

Journal Of Dairy Research \& Technology | ISSN: 2688-9315

Journal Of Dentistry Oral Health \& Cosmesis | ISSN: 2473-6783

Journal Of Diabetes \& Metabolic Disorders | ISSN: 2381-201X

Journal Of Emergency Medicine Trauma \& Surgical Care | ISSN: 2378-8798

Journal Of Environmental Science Current Research | ISSN: 2643-5020

Journal Of Food Science \& Nutrition | ISSN: 2470-1076

Journal Of Forensic Legal \& Investigative Sciences | ISSN: 2473-733X

Journal Of Gastroenterology \& Hepatology Research | ISSN: 2574-2566
Journal Of Genetics \& Genomic Sciences | ISSN: 2574-2485

Journal Of Gerontology \& Geriatric Medicine | ISSN: 2381-8662

Journal Of Hematology Blood Transfusion \& Disorders | ISSN: 2572-2999

Journal Of Hospice \& Palliative Medical Care

Journal Of Human Endocrinology | ISSN: 2572-9640

Journal Of Infectious \& Non Infectious Diseases | ISSN: 2381-8654

Journal Of Internal Medicine \& Primary Healthcare | ISSN: 2574-2493

Journal Of Light \& Laser Current Trends

Journal Of Medicine Study \& Research | ISSN: 2639-5657

Journal Of Modern Chemical Sciences

Journal Of Nanotechnology Nanomedicine \& Nanobiotechnology | ISSN: 2381-2044

Journal Of Neonatology \& Clinical Pediatrics | ISSN: 2378-878X

Journal Of Nephrology \& Renal Therapy | ISSN: 2473-7313

Journal Of Non Invasive Vascular Investigation | ISSN: 2572-7400

Journal Of Nuclear Medicine Radiology \& Radiation Therapy | ISSN: 2572-7419

Journal Of Obesity \& Weight Loss | ISSN: 2473-7372

Journal Of Ophthalmology \& Clinical Research | ISSN: 2378-8887

Journal Of Orthopedic Research \& Physiotherapy | ISSN: 2381-2052

Journal Of Otolaryngology Head \& Neck Surgery | ISSN: 2573-010X

Journal Of Pathology Clinical \& Medical Research

Journal Of Pharmacology Pharmaceutics \& Pharmacovigilance | ISSN: 2639-5649

Journal Of Physical Medicine Rehabilitation \& Disabilities | ISSN: 2381-8670

Journal Of Plant Science Current Research | ISSN: 2639-3743

Journal Of Practical \& Professional Nursing | ISSN: 2639-568

Journal Of Protein Research \& Bioinformatics

Journal Of Psychiatry Depression \& Anxiety | ISSN: 2573-0150

Journal Of Pulmonary Medicine \& Respiratory Research | ISSN: 2573-0177

Journal Of Reproductive Medicine Gynaecology \& Obstetrics | ISSN: 2574-2574

Journal Of Stem Cells Research Development \& Therapy | ISSN: 2381-2060

Journal Of Surgery Current Trends \& Innovations | ISSN: 2578-7284

Journal Of Toxicology Current Research | ISSN: 2639-3735

Journal Of Translational Science And Research

Journal Of Vaccines Research \& Vaccination | ISSN: 2573-0193

Journal Of Virology \& Antivirals

Sports Medicine And Injury Care Journal | ISSN: 2689-8829

Trends In Anatomy \& Physiology | ISSN: 2640-7752

Submit Your Manuscript: https://www.heraldopenaccess.us/submit-manuscript 